\title{
Safra kesesi kanserine bağlı gelişen hemobilinin başarılı tedavisi
}

\section{Successfull treatment of hemobilia due to gall bladder carcinoma}

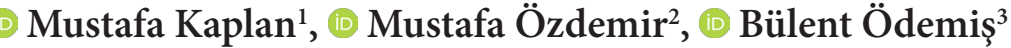 \\ ${ }^{1}$ Ahi Evran Üniversitesi Eğitim ve Araştırma Hastanesi, Gastroenteroloji Kliniği, Kırşehir, Türkiye \\ ${ }^{2}$ Ankara Bilkent Şehir Hastanesi, Radyoloji Kliniği, Ankara, Türkiye \\ ${ }^{3}$ Ankara Bilkent Şehir Hastanesi, Gastroenteroloji Kliniği, Ankara, Türkiye
}

Cite this article as / Bu makaleye atıf için: Kaplan M, Özdemir M, Ödemiş B. Safra kesesi kanserine bağlı gelişen hemobilinin başarılı tedavisi. Anatolian Curr Med J 2020; 2(3): 91-93.

\begin{abstract}
ÖZ
Hemobili, hepatobiliyer trakttan kaynaklı kanama olup üst gastrointestinal kanamanın nadir bir sebebidir. Hemobilinin en yaygın nedenleri iyatrojenik, travmatojenik ve neoplastik nedenlerdir. Tedavide ise endoskopik olarak kanama kontrolü ve kanayan damarın anjiyografik olarak embolizasyonu kombine olarak kullanılmaktadır. Biz bu vakada 71 yaşında inoperabl safra kesesi kanseri tanısı olup hemobili ve biliyer obstruksiyon semptomları ile başvuran bir hastanın tedavisinden bahsedeceğiz.
\end{abstract}

Anahtar kelimeler: ERCP, sistik arter embolizasyonu, gastrointestinal kanama

\begin{abstract}
Hemobilia is bleeding from the hepatobiliary tract and a rare cause of acute upper gastrointestinal bleeding. The most common causes of hemobilia are iatrogenic, traumatogenic, and neoplastic. In the treatment, endoscopic bleeding control and angiographic embolization of the bleeding vessel are used in combination. In this case report, we present a 71-year-old patient with inoperable gallbladder cancer who presented with hemobilia and biliary obstruction symptoms.
\end{abstract}

Keywords: ERCP, cystic artery embolisation, gastrointestinal bleeding

\section{GİRIŞ}

Hemobili, hepatobiliyer trakttan kaynaklı kanama olup üst gastrointestinal kanamanın nadir bir sebebidir (1). Hemobili vakalarının çoğunluğu safra yolundan veya karaciğer manipülasyonundan kaynaklanan iyatrojenik bir nedene sahiptir. Künt travma da hemobilinin önemli bir nedenidir. Hemobilinin diğer nadir nedenleri ise duktal parazitler, hepatik tümörler, hepatik arter anevrizma rüptürü, hepatik abse ve koledokolitiazistir (2). Sağ üst kadran ağrısı, sarılık ve üst gastrointestinal kanama klasik üçlü triaddır ancak nadir görülür. Bilgisayarlı tomografi ve manyetik rezonans görüntüleme tercih edilen tanı yöntemleridir (3). Tercih edilen tedavi

yöntemleri ise transkatater arteryal embolizasyon ve endoskopik olarak kanama kontrolünün sağlanmasıdır (4). Cerrahi nadiren terapötik bir seçenektir. Biz bu vakada 71 yaşında inoperabl safra kesesi kanseri tanısı olup hemobili ve bilier obstuksiyon semptomları ile başvuran bir hastanın tedavisinden bahsedeceğiz.

\section{OLGU}

Yetmiş bir yaşında kadın hasta kliniğimize hematemez ve karın ağrısı şikayeti ile başvurdu. Labaratuvar incelemesinde hemogobin: $9 \mathrm{~g} / \mathrm{dL}$, AST: $151 \mathrm{U} / \mathrm{L}$, 
ALT: 145 U/L, ALP: 219 U/L, GGT: 514 U/L, total biluribin: 4,1 $\mathrm{mg} / \mathrm{dL}$ ve direkt biluribin: $2,1 \mathrm{mg} / \mathrm{dL}$ saptand1. Hikayesinde bir y1l önce inoparabl safra kesesi karsinomu tanısı aldığ 1 ve kemoradyoterapi aldığ öğrenildi. Üst gastrointestinal endoskopide ikinci kıtada papil hizasından distale doğru uzanan lümende taze kan birikintileri izlendi. Duodenoskop ile değerlendirmede papil orifisinden dışarı protrüde olmuş pıhtı görüldü. Endoskopik retrograd kolanjiyopankreatografi (ERCP) yapıldı ve kolanjiogramda koledok içerisinde koagulumla uyumlu dolum defektleri izlendi. Hastada safra kesesi tümörüne bağlı hemobili düşünülerek koledoktan bol miktarda pihtı temizlendikten sonra (Resim 1) sol dala uzanacak şekilde $7 \mathrm{~F}$ nazobilier drenaj kateteri (NBD) konuldu.

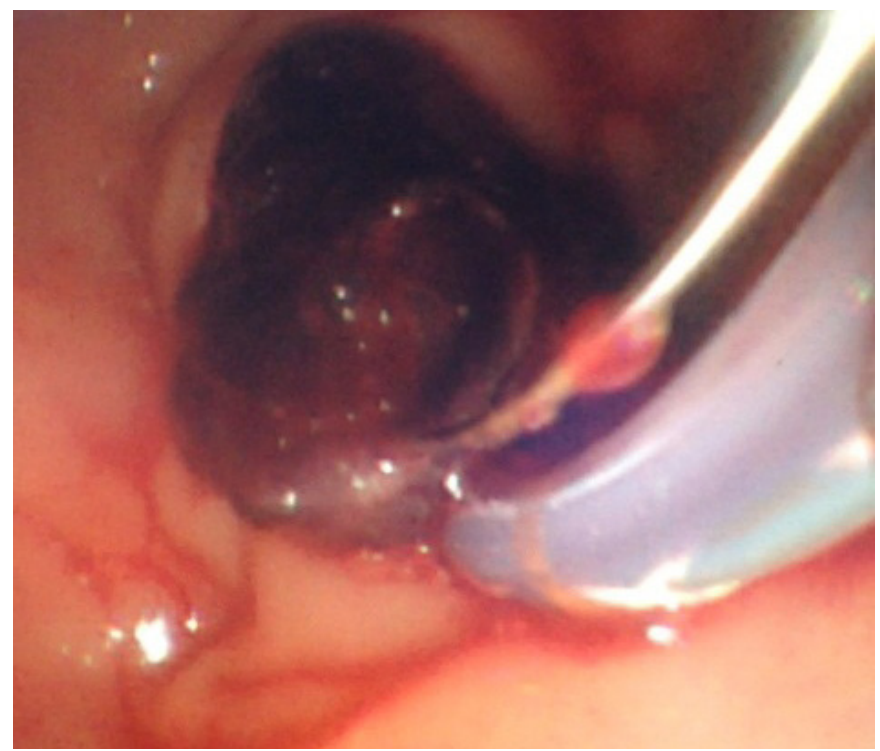

Resim 1. Papilden temizlenen koagulum artıkları

Kanaması devam eden ve hemoglobin değerlerinde düşme olan hastaya abdominal tomografi çekildi ve sistik arter kaynaklı kanama olduğu görüldü (Resim 2).

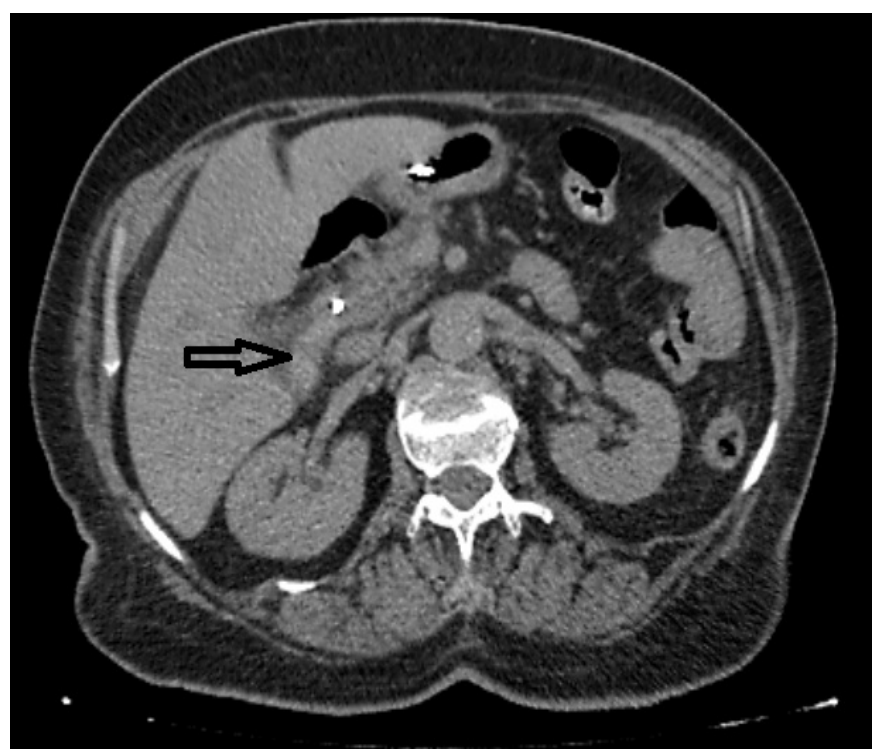

Resim 2. Tomografide prekontrast serilerde sistik kanal içerisinde hafif hiperdens hemoraji
Kanama kontrolü için yapılan hepatik anjiografide kitle lokalizasyonuna uyan ve anormal genişleme, dallanma gösteren iki adet sistik arter dalı izlendi (Resim 3).

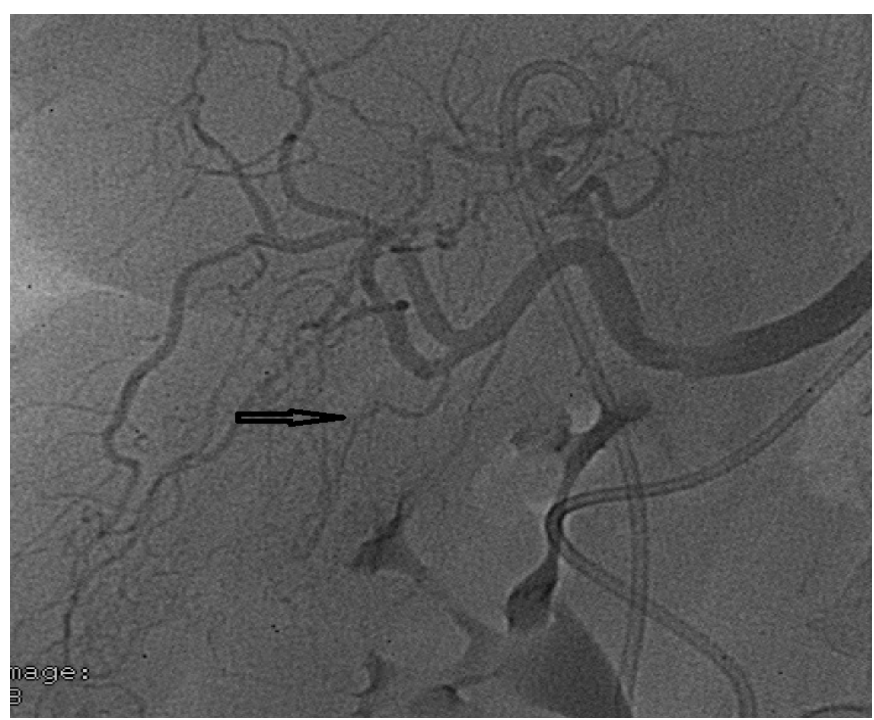

Resim 3. Anjiyografide embolizasyon öncesi kanayan sistik arter

$\mathrm{Bu}$ dallar mikrokateter ile selektif kateterize edilerek 500-700 mikron mikrosferik embolizasyon partikülü ile embolize edildi (Resim 4).

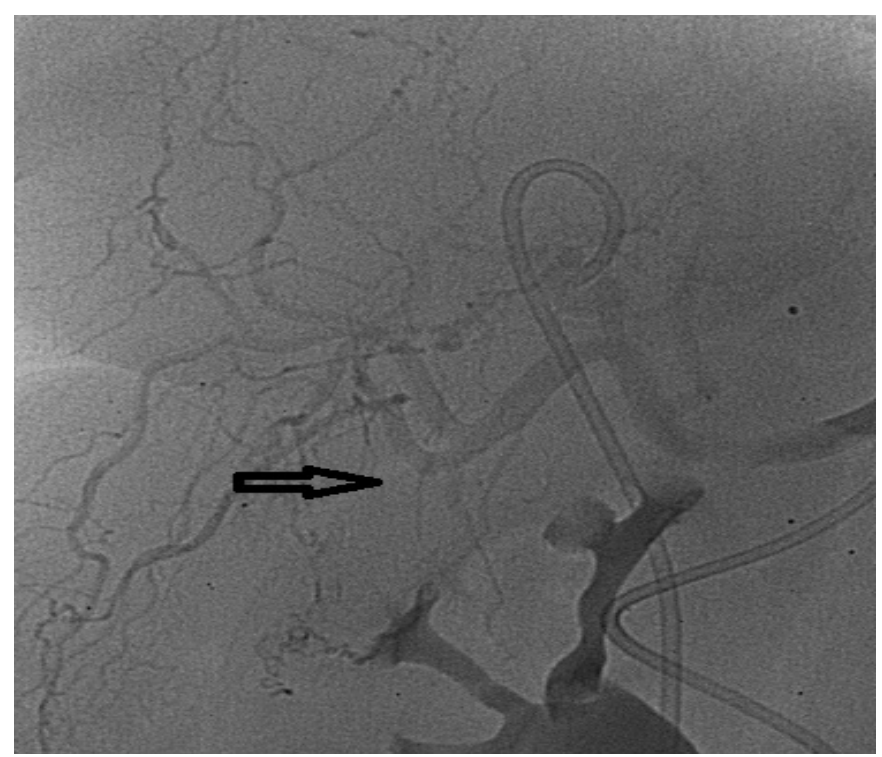

Resim 4. Anjiyografi sonrası oklude sistik arter

Takiplerinde hastanın NBD'den kanlı geleni azalması üzerine hastanın NBD'si çekilerek koledoğa stent konuldu. Genel durumu iyi vitalleri stabil hasta önerilerle taburcu edildi.

\section{TARTIŞMA}

Hemobili üst gastrointestinal kanamanın nadir bir sebebi olup etyolojsi bulunamayan ve hikayesinde biliyer trakt veya pankreas hastalığı bulunan her hastada akılda 
tutulmalıdır. Ayırıcı tanıda diğer üst gastrointestinal kanama nedenleri ve özellikle 'hemosuccus pancreaticus' düşünülmelidir (5). Genel olarak hastalarda nadiren görülen klasik ağrı, sarılık ve kanama triadı bizim hastamızda görülmüştür. Bu durum da hastalığın tanısını kolaylaştırmıştır. Hastalığın tanısında ERCP ile safra yollarının görüntülenmesi çoğu zaman yeterli olmakla birlikte altın tanı anjiyografi olmaya devam etmektedir. Bizim vakamızda da ERCP tanı ve tedavi amacıyla kullanılmış ancak ERCP ile yapılan tedavi başarılı olmadığ 1 için hastaya transkateter arteryal embolizasyon uygulanmıştır. Zaten literatürde de bu iki tedavinin kombine olarak kullanılması önerilmektedir (6). ERCP ile safra yollarındaki pıhtıları temizlemek mümkünken primer odağa çoğu zaman müdahale edilememektedir. Anjiyografik yöntemlerle hemobiliye sebep olan damarın bulunması ve embolizasyonu çoğu zaman kesin tedavi edici olmaktadır. Ancak bizim vakamızda olduğu gibi altta yatan inoperabl tümörü olan olgularda yeni damar oluşumları ile tekrar kanama olabilmektedir (6).

Hemobili genellikle arteryel orjinli olup venöz sistemik basıncının daha düşük olması nedeniyle venöz kanamalar çok daha seyrektir. Kanama odağ 1 çoğunlukla karaciğer, safra kesesi, safra yolları ve pankreastır. Bismuth (7)'un yayınladığı 55 vakalık hemobili serisinde, vakaların \%53'inde kanama yerini karaciğer, \%23'ünde safra kesesi, \%22'sinde safra yolları ve \%2'sinde ise kanama odağını pankreas olarak raporlamıştır. Bismuth'un çalışmasında da belirtildiği gibi hemobilinin sik sebeplerinden biri safra kesesi kaynaklı kanamalardır ancak bu vakaların çoğunda sebep iyatrojenik veya tramvatojenik yaralanmalardır. Literatürde safra kesesi kanserine bağlı gelişen hemobili vakaları ise kısıtlıdır $(8,9)$. Bu olgu sunumunda da safra kesesi kanserine bağlı nadir görülen bir hemobili vakasından bahsedildiğinden bu çalışmanın literatüre katkı sağlayacağını düşünüyoruz.

\section{SONUÇ}

Hemobilinin nadir bir üst gastrointestinal kanama nedeni olduğu ve endoskopik ve anjiyografik yöntemlerle başarılı bir şekilde tedavi edilebileceği akılda tutulmalıdır.

\section{ETIIK BEYANLAR}

Aydınlatılmış Onam: Çalışmaya katılan hastadan yazılı bilgilendirilmiş onam alınmıştır.

Hakem Değerlendirme Süreci: Harici çift kör hakem değerlendirmesi.

Çıkar Çatışması Durumu: Yazarlar bu çalışmada herhangi bir çıkara dayalı ilişki olmadığını beyan etmişlerdir.
Finansal Destek: Yazarlar bu çalışmada finansal destek almadıklarını beyan etmişlerdir.

Yazar Katkıları: Yazarların tümü; makalenin tasarımına, yürütülmesine, analizine katıldığını ve son sürümünü onayladıklarını beyan etmişlerdir.

\section{KAYNAKLAR}

1. Green M, Duell R, Johnson C, Jamieson N. Haemobilia. Br J Surg 2001; 88: 773-86.

2. Cathcart S, Birk JW, Tadros M, Schuster M. Hemobilia: An Uncommon But Notable Cause of Upper Gastrointestinal Bleeding. J Clin Gastroenterol 2017; 51: 796-804.

3. Berry R, Han JY, Kardashian AA, LaRusso NF, Tabibian JH. Hemobilia: etiology, diagnosis, and treatment. Liver Res 2018; 2: 200-8.

4. Zhornitskiy A, Berry R, Han JY, Tabibian JH. Hemobilia: Historical overview, clinical update, and current practices. Liver Int 2019; 39: 1378-88.

5. Bektas M. Hemobilia and Hemosuccus Pancreaticus. Turkiye Klinikleri J Gastroenterohepatol-Special Topics 2008; 1: 32-4.

6. Khamaysi I, Suissa A. Hemobilia. Gastrointest Endosc 2017; 86: 1176-7.

7. Bismuth H. Hemobilia. N Engl J Med 1973; 288: 617-9

8. Sadamori H, Fujiwara H, Tanaka T,ve ark. Carcinosarcoma of the gallbladder manifesting as cholangitis due to hemobilia. J Gastrointest Surg 2012; 16: 1278-81.

9. Páez Cumpa C, Erimeiku Barahona A, Payeras Capó MA, Amengual Antich I, Garrido Durán C. Hemobilia due to intracholecystic papillary neoplasm. Rev Esp Enferm Dig 2017; 109: 70-3. 